\title{
AS ESTRUTURAS GEODÉSICAS DO ECOCAMP NA PATAGÔNIA: UM ESTUDO SOBRE SEUS ASPECTOS ERGONÔMICOS E SUSTENTÁVEIS
}

\author{
Theska Laila de Freitas Soares (1); \\ Amilton José Vieira de Arruda (2) \\ (1) Universidade Federal de Pernambuco, especialista em Design de Produtos \\ e-mail: theskalaila7@gmail.com \\ (2) Universidade Federal de Pernambuco, Doutor em Design \\ e-mail: arruda.amilton@gmail.com
}

\begin{abstract}
RESUMO
Este trabalho se propõe a apresentar um estudo sobre os aspectos ergonômicos tais como percepção ambiental, acessibilidade e conforto térmico, dentre outros, do hotel EcoCamp na Patagônia relativos a análise do ambiente construído, porém, atentando também para os aspectos sustentáveis, por acreditar que há uma tendência/urgência no cenário atual em colocar em foco estas questões e creditá-las de igual importância, colaborando assim com os estudos da Ergonomia do Ambiente Construído que ainda oferece muitas oportunidades para se desenvolver, e também tornar mais conhecidas as estruturas geodésicas e suas vantagens num contexto de sustentabilidade.
\end{abstract}

\begin{abstract}
This scientific research aims to present a study on the ergonomic aspects such as environmental awareness, accessibility and thermal comfort, among others, about the hotel EcoCamp in Patagonia on the analysis of the built environment, however, paying attention also to the sustainable aspects, believing there is a tendency and urgency in the current scenario to put into focus these issues and credit them of equal importance, thus contributing to the studies of Ergonomics Built Environment which still offers many opportunities to develop, and also make the geodesic structures best known and its advantages in a context of sustainability.
\end{abstract}

\section{INTRODUÇÃO}

Para IIDA (2005) a Ergonomia é o estudo das interações das pessoas com a tecnologia, a organização e o ambiente, objetivando intervenções e projetos que visem melhorar a segurança, o conforto, o bem-estar e a eficácia das atividades humanas. Em se tratando de ambiente, ele é considerado ergonomicamente adequado quando atende às necessidades físicas e cognitivas das pessoas que o vivenciam. 
Embora a ergonomia do ambiente construído venha contribuindo no sentido de prover novas abordagens às questões que concernem à adaptabilidade dos ambientes e às necessidades dos indivíduos na realização de suas tarefas e atividades, precisa ainda percorrer um longo caminho em direção a consolidação de seus conceitos e metodologias, por isto é importante trazer projetos diferentes do usual para se identificar novas abordagens e fazer pensar mais sobre o ambiente construído.

Desta forma, traz uma análise sobre o hotel EcoCamp na Patagônia, em conformidade com os mais elevados padrões internacionais de gestão ambiental e que ganhou uma reputação premiada pelas suas políticas de sustentabilidade e uso inovador de tecnologia verde, em especial através do seu layout ousado propiciado pela adoção de de cúpulas geodésicas para os principais ambientes do hotel, tais como as áreas privadas para dormir e as áreas comunitárias para refeições, dentre outras, se traduzindo como uma proposta bastante vantajosa e promissora para projetos futuros. O estudo não será pormenorizado em metodologias específicas e detalhes técnicos pois o objetivo é apenas o de observar que essa construção concentrou um esforço maior em questões ambientais, mais nem por isto a ergonomia foi desprivilegiada.

Então, de maneira nenhuma o intuito deste artigo é o de discordar da visão sistêmica do espaço construído conferida pela abordagem ergonômica, que avança para um entendimento de que a adequação dos espaços aos usuários possa produzir edifícios que favorecem o bom desempenho das atividades e ainda, a aspectos de acessibilidade. Mas o que se deseja é interrogar sobre o foco como elemento primordial e fundamental ser apenas o usuário, tomado na total complexidade do ser humano, em seus aspectos físicos, culturais, psicossociais e cognitivos, se apenas este deve mesmo ser tomado como peça fundamental do processo de projetação, ou se há espaço para um contexto mais amplo, como o da sustentabilidade, se há espaço para que tais aspectos possam configurar também como peças chaves nas análises dos ambientes, acreditando que o mundo caminha para um consenso de anseios ambientais, e porque não incorporar a adequação à função que desempenhará tal espaço a estas questões.

\section{AS ESTRUTURAS GEODÉSICAS}

Em 1922, Bauersfeld, cientista alemão chefe de design da indústria ótica Carls Zeiss, desenvolveu a primeira cúpula geodésica revestida de cimento para abrigar um planetário. Mas foi Buckminster Fuller quem descobriu as leis formadoras destas estruturas, construindo e divulgando suas propriedades em inúmeros estudos de otimização, conseguindo por isto, a patente de $\mathrm{n}^{\circ} 2.682 .235$ referente a cúpula geodésica em 1954 e transformando-a num ícone da arquitetura moderna da década 50. (FORLANI, 1983)

A estrutura Geodésica corresponde a uma malha triangular, cujos vértices estão inscritos na superfície de uma esfera que, na maioria das vezes, deriva de poliedros regulares platônicos com face triangular, onde o mais comum a ser utilizado, inclusive por Fuller é o icosaedro (com 20 lados), por ser o mais arredondado. Uma esfera geodésica se refere a estrutura completa, e o domo ou cúpula geodésica (Figura 1) quando incompleta, configurar mais ou menos um hemisfério. 
Figura 1 - Busckminster Fuller e sua cúpula da EXPO de 1967 em Montreal no Canadá.

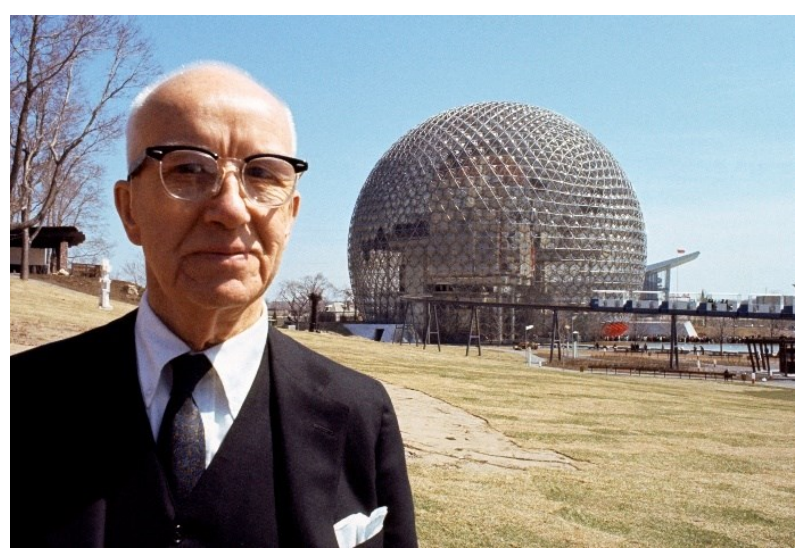

Fonte: (http://buckminsterfullerfilm.com/wp-content/uploads/2015/02/PAR142514.jpg)

Para gerar diferentes estruturas geodésicas a partir do icosaedro, basta aumentar o número de frequência, ou seja, subdividir as faces triangulares em triângulos cada vez menores, quanto mais alta a frequência, maior o número de triângulos no qual sua superfície será subdividida e mais a sua aparência torna-se arredondada. Um icosaedro é considerado uma esfera geodésica de frequência 1. Cúpulas e esferas geodésicas podem configurar em diferentes frequências para o mesmo diâmetro. (SOARES et al, 2016) Ver Figura 2 abaixo:

Figura 2 - Esferas geodésicas de diferentes frequências

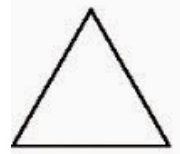

$1 \vee$
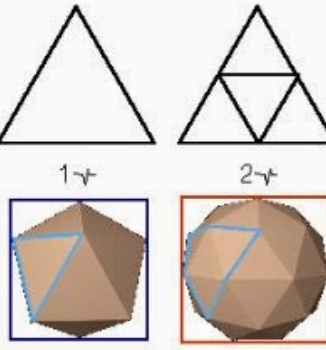

$2 \gamma$
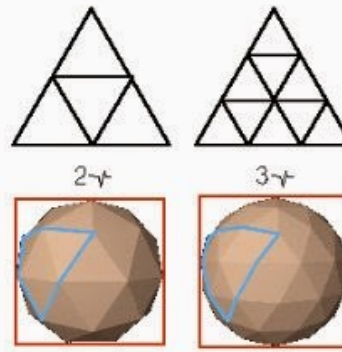

$3 \gamma$
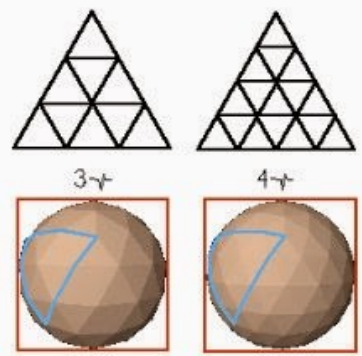

$4 x$

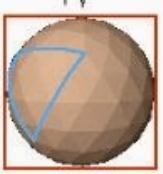

Fonte: (http://ebioconstrucao.blogspot.com.br)

Embora existam outras possibilidades de sistemas construtivos de uma cúpula Geodésica, a mais básica é composta por três elementos principais: as Barras, os Nós (conectores das barras) e o Sistema de Cobertura (se a estrutura for fechada), o que torna o seu sistema construtivo mais simples que os métodos tradicionais de alvenaria.

Além disso, VERSCHLEISSER (2008) ratifica que as cúpulas geodésicas possuem auto sustentação com extraordinária resistência e leveza devido à sua forma esférica e às formas geométricas que as constituem, elas se comunicam e se apoiam umas nas outras criando um sistema chamado por Fuller de tensegridade, em que qualquer força aplicada em uma delas retransmite a tensão e a distribui igualmente entre as demais até a sua base, assim como os arcos na engenharia.

Grande parte dessa vantagem estrutural vem da enorme estabilidade proporcionada por sua malha triangular. Um triângulo é um elemento estável independente do seu tamanho, são as únicas formas que permanecem rígidas, mesmo quando construídas 
com conexões flexíveis, tendo cada vértice estabilizado pelo lado oposto. O mesmo não ocorre com quadrados, pentágonos, hexágonos, por exemplo, que quando construídos com conexões flexíveis, tendem a deformar, se tornando por isto, mais instáveis. Portanto, os sólidos esféricos derivados de outra malha que não a triangular, só são adequados em aplicações especiais e/ou em conjunto com a malha triangular. (PEARCE,1980)

\section{O HOTEL ECOCAMP PATAGÔNIA}

O EcoCamp é um hotel localizado dentro de um parque natural na Patagônia (Chile) com vista privilegiada para a região montanhosa Torres del Paine. Fundado em 2001 pelos engenheiros e proprietários da Cascada Expediciones (empresa de turismo aventureiro) Javier Lopez, Yerko Ivelic e Nani Astorga, foi o pioneiro em construir quartos de hotel com cúpulas geodésicas, cujas configurações também são uma referência para as originais cabanas indígenas da região.

Similar como nos hotéis tradicionais que possuem várias opções de quartos, no EcoCamp existem 4 opções de cúpulas para hospedagem: Standard com 10m², Suíte com $28 m^{2}$, Loft com $37 m^{2}$ e Superior com $23 m^{2}$. Os locais para as refeições, aulas de yoga, loja e bar são cúpulas geodésicas comunitárias que fornecem um ponto de encontro onde hóspedes podem compartilhar histórias entre si e planejar futuras excursões. Na Figura 3 observa-se imagens evidenciando o hotel com detalhes do exterior e interior das diferentes cúpulas geodésicas, retiradas do site da empresa.

Figura 3 - Cúpulas geodésicas do hotel EcoCamp (detalhes do Exterior e Interior)

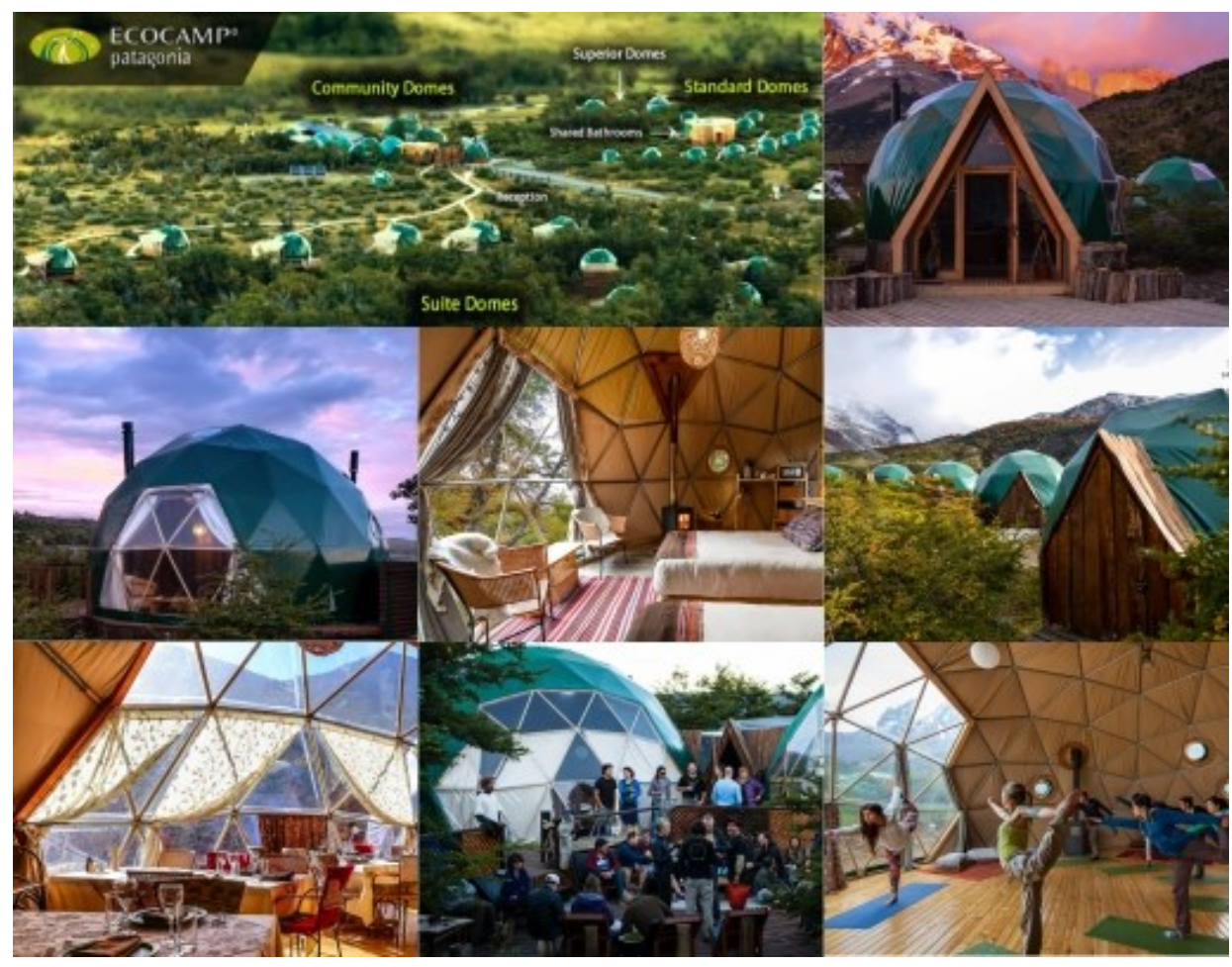

Fonte: (http://www.ecocamp.travel) 


\section{ASPECTOS ERGONÔMICOS E SUSTENTÁVEIS DO ECOCAMP PATAGÔNIA}

Para VILLAROUCO (2008) o espaço construído não pode ser concebido apenas como uma sucessão de septos que separam o exterior do interior, nem deve ser visto como elemento estático, mas como organismo vivo que interage, conduz, viabiliza, abriga, aquece e conforta quem o utiliza, sendo definidor em si mesmo, das possibilidades de seu uso.

Sendo assim, a ergonomia do ambiente vai além das questões puramente arquitetônicas, focando seu posicionamento na adaptabilidade e conformidade do espaço às tarefas e atividades que neles se irão desenvolver. Tal entendimento estabelece a necessidade de uma abordagem sistêmica quando se trata de avaliar o ambiente sob a ótica da ergonomia. Uma completa avaliação ergonômica do ambiente abrange, portanto, um vasto leque de variáveis, demandando esforços a partir de diversas áreas envolvidas no processo de projetação do espaço edificado. (VILLAROUCO, 2008)

Desta forma, além de abordar alguns dos aspectos levantados por VILLAROUCO (2008) relativos a ergonomia do ambiente construído tais como: Conforto Térmico, Acústico e Lumínico, Acessibilidade e Percepção Ambiental; também discorrerá sobre aspectos da Sustentabilidade, por acreditar estarem de acordo com as tendências /urgências atuais, não devendo se dissociarem, mas sim, serem tratados com o mesmo grau de importância. São eles:

\subsection{Conforto Térmico, Acústico e Lumínico}

A geometria das geodésicas favorece um fluxo melhorado do ar, a concentração de luz e calor e a uma temperatura mais uniforme do que numa habitação convencional. A área de superfície exposta no exterior nas cúpulas também é menor, permitindo menos troca de calor com o ambiente; aliado a isso, o volume de ar dentro da cúpula também é menor, o que se traduz em economia para se manter mormo no inverno, ou frio no verão, poupando-se até $50 \%$ em energia para aquecer ou esfriar. A distribuição excelente do fluxo de ar no interior das cúpulas evita ainda as áreas de estancamento de ar e, por conseguinte, que haja proliferação de fungos, bactérias e umidade.

As áreas translúcidas da cobertura das cúpulas as tornam naturalmente como excelentes coletoras de energia solar, refletindo a luz e o calor para dentro da estrutura como uma estufa, evitando a perda do calor por irradiação. Essa situação se torna muito útil para regiões com inverno rigoroso como na Patagônia, onde mesmo sem paredes de alvenaria, com a ajuda da lareira à lenha, do aquecimento solar, e da aparente estrutura de ferro galvanizado com a cobertura exterior de lona verde e transparente, mais uma camada interna de almofada isolante são eficientemente suficientes para garantir calor e proteção contra os ventos fortes e frios do local. Aliado $a$ isto, o conforto térmico também é garantido por um sistema à gás para 0 aquecimento da água.

Sobre o conforto acústico, LOTUFO et al (1981) ressalta ainda a qualidade acústica proporcionada no interior das cúpulas, a geometria favorece que o som seja reverberado dentro delas e que se torne uma barreira para os sons de fora. No caso do hotel, esta qualidade pode ser aproveitada dentro das cúpulas para o convívio 
social com apresentações musicais e a privacidade pode ser garantida com a distância dada entre estas cúpulas. Por estar numa região de ventos fortes, o formato ajuda a diminuir um pouco o ruído externo, embora permitindo ainda que os sons da natureza sejam aproveitados, o que não deixa de ser um ponto positivo.

Já a iluminação do hotel privilegia a luz natural na maior parte do dia. Dentro das cúpulas há claraboias que facilitam a captação da luz de dia e durante a noite há a iluminação por lâmpadas e lanternas de led provenientes da energia verde de células fotovoltaicas de captação de energia solar. Ela é suficiente, mas um ponto negativo é que na versão da cúpula Standard é necessário solicitar lanternas pois a iluminação é inexistente, chegando a ficar comprometida nas outras áreas do hotel nos dias de inverno rigoroso quando a iluminação solar é precária, utilizando-se apenas de um gerador elétrico.

\subsection{Acessibilidade}

Apesar da proposta do hotel ser claramente direcionada para um público ativo em busca de aventura, esportista, o que é evidenciado pelos programas de atividades disponíveis no hotel como trilhas à pé, de bicicleta ou à cavalo por terrenos irregulares, picos, pontes de madeiras ou mesmo loga, canoagem, é importante também discorrer sobre à facilidade de deslocamentos entre os ambientes construídos do hotel, para pessoas com dificuldades de locomoção, como cadeirantes e idosos. Aqui, isto se torna um ponto negativo, pois não há rampas e como as construções são suspensas, mesmo por plataformas de madeira relativamente baixas, há sempre escadas $\mathrm{e}$ batentes dificultando as passagens. A versão Standard com apenas $10 \mathrm{~m}^{2}$ também não é adequada para cadeirantes, embora nas demais áreas, o fato das cúpulas serem maiores e livres de paredes internas contribui para um deslocamento sem obstrução. Idosos também podem se sentir desencorajados a ficar nas cúpulas mais afastadas das áreas comunitárias pois teriam que fazer longas caminhadas para ir e vir, embora para alguns isto não chegue a ser um problema excludente.

Sobre esta acessibilidade para pessoas com deficiências visuais, estas também sentiriam certa dificuldades por causa dos batentes e escadas, mas também não seria um total empecilho, principalmente se estiverem acompanhadas. Os deficientes auditivos não teriam problemas com deslocamentos nos ambientes do hotel pois são bem intuitivos com as passarelas de madeira fazendo a ligação entre todas as cúpulas, mas, podem sentir dificuldade de comunicação, caso estejam desacompanhados e não haja pessoa do hotel capacitada para a linguagem de sinais.

Entretanto, um ponto positivo do hotel se refere a acessibilidade de maneira mais abrangente, se preocupando com o entorno do ambiente a qual está inserido, e isto pode ser observado no planejamento das construções das cúpulas sobre plataformas elevadas e na ausência de cercas em torno do EcoCamp, o que permite que a passagem de animais por baixo das estruturas não seja bloqueada e que cavalos possam entrar livremente para pastar. Lâmpadas solares iluminam as passarelas e as cúpulas à noite, sendo muito sutis, de modo a não perturbar os animais noturnos, incluindo os pumas, esta é a prova de que eles não se sentem ameaçados pelo hotel. Não pensar apenas na acessibilidade do Homem no projeto do ambiente construído, mas também na dos animais que vivem no local não deixa de ser um enfoque 
inovador, de acordo com as tendências atuais de preocupação ambiental e que também merece ser destacado.

\subsection{Percepção Ambiental}

As cúpulas oferecem um visual bem diferente e atrativo para o layout do hotel e o padrão radial permite a criação de espaços mais sociáveis. Com coberturas autossustentáveis, é possível ter amplos espaços desobstruídos sem a necessidade de vigas, colunas ou paredes de suporte no interior, e isto tende a aproximar ao invés de separar as pessoas. Outra observação pertinente é que psicologicamente o redondo é muito mais acolhedor que o ortogonal utilizando o exemplo da sensação de opressão transmitida por uma laje plana em cima da cabeça em detrimento da curvatura côncava no interior da cúpula, que por maior que seja, se percebe acolhedor.

Todas as cúpulas de dormir são confortáveis, mesmo a versão menor, a Standard, em que o banheiro é compartilhado e não possui sistema de aquecimento, nem iluminação. As demais versões possuem área espaçosa para camas, lareira, banheiro privativo com sistema de compostagem, aquecimento de água à gás e energia elétrica para carregamento de celulares e laptops derivada da energia solar, não possui wifi, nem se pode utilizar secadores pois o consumo de energia é limitado. O objetivo é ter uma experiência mais natural possível dentro do que é possível em termos de conforto de interação com a natureza, mas tudo é pensado para que se perceba a premissa do hotel de preocupação e responsabilidade ambiental.

O aspecto social é um dos atributos mais célebres do hotel, que promove atividades e passeios em grupos e estimula o convívio. Há quatro cúpulas de uso comunitário, elas são ligadas às demais cúpulas de dormir por passarelas de madeira suspensas. Uma delas é o refeitório onde todos comem juntos, a outra, um bar/lounge, uma terceira é destinada à prática de loga e uma última contém uma loja e uma pequena biblioteca. Nelas, os hóspedes podem interagir entre si, sentar, ler, conversar, fazer ioga, desfrutar da boa gastronomia do hotel, relaxar, compartilhar suas histórias e aventuras do dia, etc. Usualmente os guias também utilizam a cúpula comunitária da biblioteca para mostrar aos hóspedes os mapas das trilhas e pontos de observação de animais selvagens. Todas as cúpulas comunitárias estão rodeados por terraços, com amplo espaço para favorecer a interação social.

Apesar de ter uma configuração diferente do usual, as cúpulas são muito bem vistas pelos visitantes que evidenciam o design original no interior de belas formas geométricas, além da aprovação da ideia de hotel verde. Em sua página do facebook, possui mais de 20.000 curtidas e uma aprovação de quase 5 estrelas, a mesma aprovação possui no Tripadvisor com quase 500 comentários de hóspedes satisfeitos com suas experiências cujos pacotes turísticos variam de $\$ 2600$ à $\$ 5300$ dólares, (incluindo: atividades, hotel, refeições e traslados).

\subsection{A Sustentabilidade das Cúpulas Geodésicas: Design Portátil}

A forma geodésica é bastante vantajosa, pois ela otimiza a carga, deslocando as forças em toda sua estrutura, por isto é ergonômico, aerodinâmico e forte para resistir a situações extremas como: ventos fortes, tempestades, terremotos e acumulação de 
neve. Quanto mais forte o vento, não tendo superfícies de sucção, ele o rodeia e o afirma mais no terreno, inclusive na região do hotel a velocidade dos ventos pode chegar à $200 \mathrm{~km} / \mathrm{h}$.

Além disso, a esfera tem $25 \%$ menos área de superfície por volume fechado do que qualquer outra forma. A cúpula combina a estabilidade inerente dos triângulos com a proporção vantajosa volume/área de superfície de uma esfera o que resulta em menos materiais de construção para incluir mais espaço. Há uma estimativa de redução de $30 \%$ de materiais e $50 \%$ de energia em relação a uma construção convencional de alvenaria de mesma área construída. Redução também de custos com a mão de obra, pois a montagem é mais fácil, simples e rápida.

Tendo menos material, menos área de superfície, ausência de paredes internas e composto de materiais mais leves que a alvenaria, como tubos de ferro galvanizado, lona, almofadas isolantes e madeira, este design portátil não precisa de um alicerce complicado, no caso do EcoCamp uma plataforma suspensa de pinho foi o suficiente, isto facilitou que em 2005 o hotel mudasse de local, indo para o pé das Torres sem deixar vestígios no local anterior, pois sendo de fácil montagem, torna-se bem indicado até mesmo para lugares remotos, como desertos, pólos, florestas, praias, montanhas, etc. Outra observação interessante sobre a composição visual do EcoCamp é que por serem verdes (cúpulas), de madeira (plataformas) e de altura limitada, se camuflam harmoniosamente na paisagem natural.

\subsection{Diminuição de Emissões de $\mathrm{CO}^{2}$}

Em 2008, tornou-se uma empresa com certificado livre de Carbono. Este certificado é possível para as empresas que visam minimizar ao máximo as emissões de $\mathrm{CO}^{2}$. A estimativa é que em 1 ano as políticas do hotel compensem cerca de 230.000 toneladas de emissões de $\mathrm{CO}^{2}$. Por comprar de fornecedores locais, seja alimentos, seja artesanato, decoração ou móveis, também evita a emissão por transportes, visto que os outros hotéis da região recebem entregas em voos provenientes da capital ou do exterior. E como oferecem expedições de aventuras, os meios de transportes que disponibilizam também são livres de emissão, tais como cavalos, bicicletas, canoas e as pernas para as caminhadas nas trilhas.

\subsection{Energia Verde}

Toda energia elétrica do hotel vem de turbinas hídricas e painéis fotovoltaicos, ou seja, obtenção de energia a partir de fontes $100 \%$ renováveis, sendo $40 \%$ solar, já que se é muito eficiente no verão, quando a Patagonia recebe até 17 horas de sol por dia, e $60 \%$ hidrelétrica. A captação de energia pelas turbinas hídricas é feita por 5 litros de água do rio que passam pelas turbinas por segundo entregando uma potência constante de 800 Watts. Um inversor é usado para alternar as baterias de $24 \mathrm{~V}$ para $220 \mathrm{~V}$, a voltagem padrão no Chile. Aliado a isso, uma matriz de 1700 painéis fotovoltaicos também ligados ao banco de baterias completam a quantidade de energia necessária para o funcionamento do Ecocamp.

Assim, estas baterias alimentam todos os frigoríficos, iluminação, electrodomésticos, aparelhos de som, etc. O gás propano só é usado para aquecer a água e as cúpulas 
superiores, mas existe um projeto piloto para aquecer a água do chuveiro também com energia solar. Com a política de economia de energia elétrica do hotel, ela é limitada e está disponível apenas para os hóspedes carregarem seus gadgets, não sendo possível utilizar para secadores de cabelo ou máquinas de barbear, por exemplo.

A implementação e manutenção de toda esta estrutura sustentável é um trabalho direto dos proprietários e engenheiros Javier e Yerko. Eles não só projetaram todo o conceito, como ensinaram, qualificaram e supervisionam toda uma equipe para manter estes recursos. (Ver esquema na Figura 4)

\section{Figura 4 - Painéis Fotovoltaicos e esquema de energia verde nas cúpulas do EcoCamp}

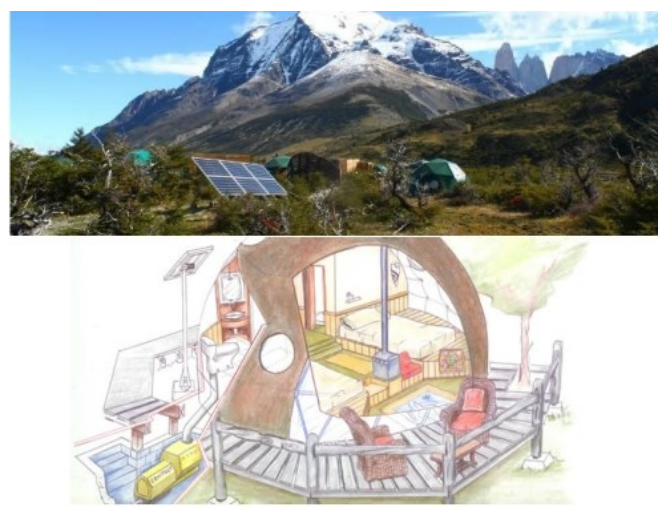

Fonte: (http://www.ecocamp.travel/en/Sustainability/Green-Energy)

\subsection{Gestão de Resíduos}

O EcoCamp possui uma gestão de resíduos que visa reduzir ao máximo o descarte de papel, latas e plástico, até os fornecedores são escolhidos com muito cuidado, garantindo que estejam cientes de cumprir com as normas ambientais do hotel que procura comprar a granel, de modo a limitar embalagens individuais a um mínimo a ser trazida para o parque. Todos os resíduos são separados de acordo com o estatuto de reciclagem: orgânico, papel, vidro e materiais perigosos ou tóxicos. Os nãoorgânicos são removidos e enviados para a cidade mais próxima de Punta Arenas para serem reciclados e o material orgânico serve de alimentação de porcos numa fazenda da vizinhança.

Guias cuidam para evitar que os hóspedes joguem lixo nas rotas durante as caminhadas, trazendo de volta para EcoCamp todo o material não-biodegradável. Há reutilização dos zip-lock do almoço e das garrafas de água e há um manual em todas as cúpulas informando as práticas ecológicas que incluem: ficar nas passarelas de madeira, não fumar dentro cúpulas, usar produtos de higiene biodegradáveis, não descartar pilhas, minimizar o tempo no chuveiro e partilhar o transporte.

Além disso, o hotel trabalha com o dispositivo de compostagem mais moderno do mundo, sendo o primeiro na indústria hoteleira em todo o Chile e Patagônia. As câmaras recolhem os resíduos dos sanitários e separam o material sólido do líquido. $O$ sólido é misturado com papel e aparas de madeira e recebe calor para manter 
microorganismos vivos e o processo de compostagem ativa. Já o material líquido passa pela câmara de limpeza onde é filtrado, em seguida, passado para a terra. Devido às baixas temperaturas na Patagônia, há um grande esforço para manter este processo.

\subsection{Responsabilidade Social}

Pensando em desenvolvimento sustentável do entorno, o apoio social mais lógico que o hotel pode oferecer é comprar localmente e empregar moradores da região, garantindo-lhes uma boa renda mensal, por isto todos os alimentos são comprados de fornecedores locais (ovos, carnes, peixes, queijos, frutas secas, grãos, marmelada, pães, frutas e legumes). Até os cavalos são contratados de fazendeiros das redondezas e a maioria do mobiliário, artesanato e decoração também são de Punta Arenas. Há uma loja no EcoCamp que vende roupas de produtores da região, principalmente de lã e couro.

Cerca de $90 \%$ de todo o pessoal empregado são da região local, sendo a maioria de Puerto Natales e de Punta Arenas, inclusive seus guias especializados cresceram na região e estudaram ecoturismo em áreas como geologia, ornitologia e botânica numa universidade. Os proprietários e o gerente são de Santiago. Todos vivem uma vida eco-friendly, cuidando da energia, água e gestão de resíduos. Compartilham a filosofia ambientalmente sustentável ao longo dos anos de existência da empresa, e incentivam os clientes, fornecedores e acionistas a pensarem e agirem da mesma forma.

A empresa ainda fomenta uma compreensão da importância da natureza entre os vizinhos, compartilhando as suas estratégias e inovações sustentáveis com o órgão de desenvolvimento da região com o intuito de ajudar outros empresários a seguirem o mesmo caminho.

Possui certificação ISO14001, até o momento, única em todo Chile, cumprindo elevados padrões ambientais e constantemente testando e partilhando novas ideias verdes, buscando ser exemplo para outros desenvolvedores de turismo; e também a ISO9001, garantindo o cumprimento dos mais elevados padrões de princípios de gestão.

Líder em viagens ambientalmente responsáveis para as áreas frágeis de recursos naturais, procura minimizar o impacto de cada visitante no Parque Nacional Torres del Paine e está constantemente a estudar, testar, comprar e instalar tecnologias sustentáveis para o fornecimento de energia verde e de gestão de resíduos.

Aqui observa-se que se leva tão a sério a questão da responsabilidade social que se percebe que a premissa é a de levar conforto aos limites somente daquilo que é sustentável, resistindo ao conceito de luxo, visto que a conservação ambiental será sempre prioridade sobre quaisquer práticas que poderiam ser prejudiciais para o parque, e este é um ponto de vista muito interessante, pois proteger o parque é ser responsável de uma maneira mais ampla, é estar preocupado com o futuro da humanidade. 


\section{CONCLUSÃO}

Energia proveniente de fontes renováveis, cúpulas que maximizam o calor e a iluminação solar, passarelas projetadas para minimizar a interrupção do terreno com o entorno, banheiros com dispositivos de compostagem, minimização de lixo e resíduos, respeito ambiental, responsabilidade social, toda uma estratégia de design voltada para criar espaços onde os viajantes possam se conectar com a natureza e explorar Torres del Paine minimizando ao máximo o impacto no ambiente, é mesmo um caminho cheio de possibilidades a ser explorado e sem dúvida, imprescindível e de suma importância para as observações de análise de um ambiente construído, se pensando de maneira mais ampla.

E é este pensar o fazer projetual que deve ser trazido à discussão. É necessário entender o conceber espaços nas diversas dimensões que o envolvem, atendendo-as igualitariamente na medida em que interferirão no desempenho futuro do projeto e mais ainda, no futuro da humanidade. É preciso expandir os horizontes da ergonomia do ambiente construído atentando para estes aspectos tão necessários. Não apenas se ater à funcionalidade dos espaços, a usabilidade e a acessibilidade e nem pensar apenas em segmentos perfeitamente harmonizados com o homem que habita e vive os ambientes, mas ir além e pensar também em seu entorno, trazer à tona essas novas questões e assumir que dessa forma o Homem pode colaborar com um todo maior, onde os benefícios são mais abrangentes.

Como pensa VILLAROUCO (2008), certamente não se pretende aqui esgotar o assunto, nem apontar o modelo delineado como caminho ideal. No entanto, firma-se o pressuposto da necessidade de conjugação de metodologias de avaliação físico espacial a fim de acrescentar mais um olhar, o da sustentabilidade, para estas análises ergonômicas de ambientes construídos.

As cúpulas e toda a visão por trás da EcoCamp é admirável, outras empresas têm usado este exemplo como projeto básico para outras cúpulas criadas na Europa, Argentina e mesmo no Chile. Parques em outras partes do mundo poderiam seguir o seu exemplo e usar alguns dos mesmos princípios, contribuindo com idéias e valores para a preservação dos recursos naturais da Terra através destas estratégias e implementação de tecnologia verde. O foco na sensibilização dos hóspedes de como cuidar do ambiente inspira o turismo de amanhã. O que se espera é que projetos como este influenciem também os novos designers a projetarem o futuro.

\section{REFERÊNCIAS BIBLIOGRÁFICAS}

FORLANI. M.C. Materiali Strutture Forme. Alinea. Firenze, 1983.

IIDA, Itiro. Ergonomia Projeto e Produção. 2. ed. rev. e ampl. Edgard Blücher. São Paulo, 2005.

LOTUFO, V. A.; LOPES, J. M. A. Geodésicas \& Cia, $1^{\text {a }}$ ed., Projeto Editores Associados Ltda. São Paulo, 1981.

PEARCE, P. Structure in Nature is a Strategy for Design. The MIT Press. Massachusetts, 1980. 
SOARES, T.L.F, et al. A Relação entre a Biomimética e a Geodésica de Buckminster Fuller no Planejamneto de Construções Sustentáveis. $7^{\circ}$ Congresso Luso Brasileiro para 0 Planejamento Urbano, Regional, Integrado e Sustentável. Maceió, 2016.

VERSCHLEISSER, R. Aplicação de Estruturas de Bambu no Design de Objetos. Como Construir Objetos Leves, Resistentes, Ecológicos, e de Baixo Custo, Tese (Doutorado em Design), Pontifícia Universidade Católica do Rio de JaneirO. Rio de Janeiro, 2008.

VILLAROUCO, Vilma. Construindo uma Metodologia de Avaliação Ergonômica do Ambiente - AVEA. Boletim da ABERGO-Associação Brasileira de Ergonomia. Ed. ABERGO: Recife, 2008. 